\title{
Reanalysis of mortality from lung cancer among diatomaceous earth industry workers, with consideration of potential confounding by asbestos exposure
}

\author{
Harvey Checkoway, Nicholas J Heyer, Paul A Demers, Graham W Gibbs
}

\begin{abstract}
Objective-To evaluate the potential for confounding from asbestos exposure, primarily chrysotile, on the relation between crystalline silica and mortality from lung cancer among diatomaceous earth (diatomite) workers.

Methods-A reanalysis of a cohort mortality study of diatomite workers was performed to take into account quantitative estimates of asbestos exposure. The reanalysis was limited to a subset of the original cohort, comprising 2266 white men for whom asbestos exposure could be reconstructed with greatest confidence. Comparisons between mortality from lung cancer (standardised mortality ratios (SMR)) were made between rates for 1942-87 for United States white men, and workers cross classified according to cumulative exposures to crystalline silica and asbestos. Comparisons of internal rates, involving Poisson regression modeling, were conducted for exposure to crystalline silica, with and without adjustment for asbestos exposure. Exposures were lagged by 15 years to take into account disease latency.
\end{abstract}

Results-There was an overall excess of lung cancer (SMR 1.41; 52 observed). The SMRs for four categories of increasing crystalline silica among the workers not exposed to asbestos were $1 \cdot 13,0.87,2 \cdot 14$, $2 \cdot 00$. An SMR of 8.31 (three observed) was found for workers with the highest cumulative exposure to both dusts. Internal analysis, after adjustment for asbestos exposure, yielded rate ratios for categories of exposure to crystalline silica: $1 \cdot 00$ (reference), 1.37, 1.80, and $1 \cdot 79$.

Conclusions-Asbestos exposure was not an important confounder of the association between crystalline silica and mortality from lung cancer in this cohort. Although based on a small number of deaths from lung cancer, the data suggest possible synergy between these exposures. An extended follow up of this cohort is in progress and should enable better assessments of independent and combined effects on risk of lung cancer.

(Occup Environ Med 1996;53:645-647)

Keywords: asbestos; crystalline silica; diatomaceous earth; lung cancer
Previously, we reported a cohort mortality study of workers exposed to crystalline silica in the diatomaceous earth (diatomite) industry. ${ }^{1}$ The principal exposure was cristobalite. Among the main study cohort of 2570 white men, there was an overall excess of lung cancer (SMR 1.43), and internal rate comparisons showed evidence of a strong doseresponse relation with cumulative exposure to crystalline silica. As chrysotile asbestos had been used in limited quantities in some diatomite mixing operations, mortality data for workers known to have worked in these areas were evaluated separately from the main study cohort; an SMR of 3.54 (four observed) was detected among these workers. ${ }^{1}$ It is now known that the extent of potential asbestos exposure resulting from employment in the mixing areas already mentioned and from maintenance activities-for example, kiln relining - may have been underestimated due to lack of detailed information available at the time of the study. Accordingly, a detailed reconstruction of asbestos exposure was undertaken. The current reanalysis was conducted to determine the extent of potential confounding by asbestos exposure on the association between crystalline silica and lung cancer found in the original study.

\section{Material and methods}

The original main study cohort comprised 2570 white male workers from two diatomite plants in southern California who had worked for at least one day between 1 January 1942 and 31 December 1987, and had attained a minimum of 12 months cumulative service. ${ }^{1}$ The reanalysis was limited to men from the larger of the two plants and to a subset of 2266 workers from this plant for whom quantitative estimates of asbestos exposure could be determined. This subset includes 89 men known to have worked in asbestos mixing jobs whose mortality experience was previously reported separately from the main study cohort. $^{1}$ Products containing asbestos were also manufactured at the smaller plant periodically since the 1950s; however, detailed information required to reconstruct past asbestos exposures was not available for this plant.

Details of the reconstruction of asbestos exposure for the larger plant are provided in a report by Gibbs and Christensen. ${ }^{2}$ Products containing chrysotile asbestos had been manufactured at this plant from the 1920s to 1977 . The most reliable information on the extent of 
Mortality from lung cancer by cumulative exposure to crystalline silica and asbestos, each lagged 15 years: 2266 white men, $1942-87$

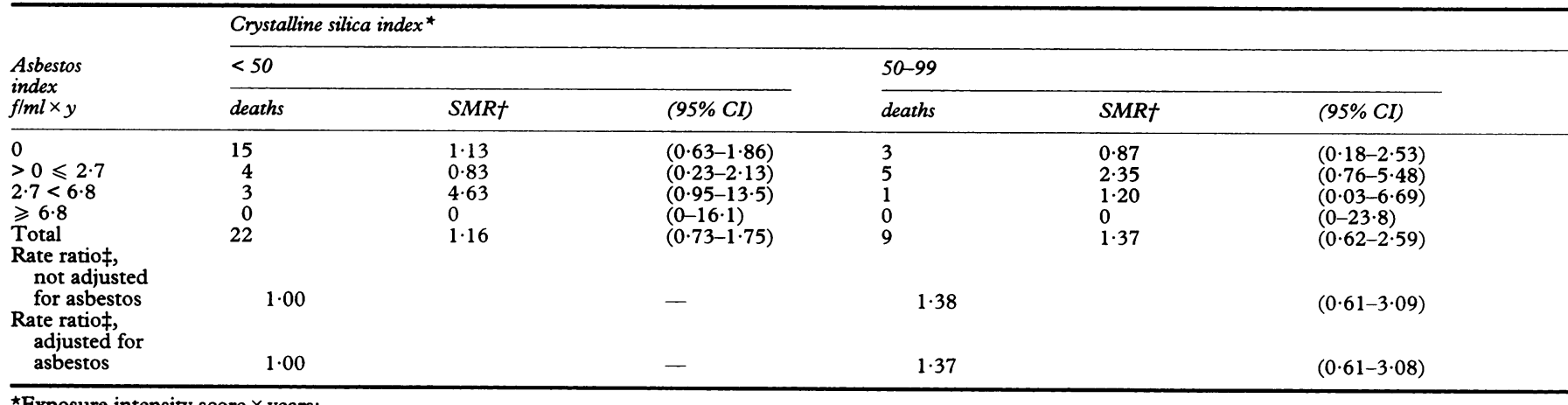

^Exposure intensity score $\times$ years;

†tandardised mortality ratio, based on rates for United States white men;

$\ddagger$ Rate ratio, from Poisson regression modelling, adjusted for age, calendar year, duration of follow up, ethnicity (Hispanic $v$ non-Hispanic).

asbestos use was available for the time after 1930; thus, workers first employed before 1930 were not included in this reanalysis. Jobs where asbestos was handled, including maintenance jobs, and quantities of asbestos included in mixed products were identified by review of historical production records and occupational hygiene records, and from interviews with management and long term workers. Exposures to asbestos other than chrysotile may have occurred episodically during maintenance activites, although measurement data by fibre type were not available. A quantitative index of asbestos exposure, in fibres $/ \mathrm{ml}(\mathrm{f} / \mathrm{ml})$, was generated for each job based on these information sources and measurements of fibre concentration reported from occupational hygiene measurement surveys. ${ }^{2}$ Cumulative exposures to crystalline silica and asbestos $(\mathrm{f} / \mathrm{ml} \times \mathrm{y})$ were estimated for each worker. The crystalline silica index was a semiquantitative measure based on duration of exposure, weighted by differences in exposure intensity between jobs and over time. ${ }^{1}$ The asbestos exposure assessment was conducted independently of the previous assessment of exposures to crystalline silica, and without knowledge of mortality outcomes of individual workers.

Mortality from lung cancer data were analysed by computing SMRs, relative to rates for United States white men in 1942-87, for workers cross classified by cumulative exposures to crystalline silica and asbestos. Boundaries of exposure categories for crystalline silica were the same as those used in the original report $(<50,50-99,100-199, \geqslant 200$ units). ${ }^{1}$ Asbestos exposure categories $(0,>0$ $<2 \cdot 7,2 \cdot 7-<6 \cdot 8, \geqslant 6.8 \mathrm{f} / \mathrm{ml} \times$ y) were chosen to match those from a study of asbestos textile workers in the United States. ${ }^{3}$ Also, we conducted Poisson regression modelling ${ }^{4}$ to estimate the internal exposure-response gradient for crystalline silica and lung cancer, with and without adjustment for asbestos exposure. Relative risks derived from the modelling were adjusted for age $(<45,45-49, \ldots 75-79, \geqslant 80)$, calendar year $(<1955,1955-59, \ldots, 1980-84$, 1985-87), duration of follow up (<10, 10-19, $\geqslant 20$ years), and ethnicity (Hispanic $v$ nonHispanic). Throughout these analyses, exposures were lagged by 15 years to allow for a disease latency interval.

\section{Results}

There were 52 deaths from lung cancer in this subset, resulting in an SMR of 1.41 (table). Among workers with $0 \mathrm{f} / \mathrm{ml} \times$ y exposure to asbestos (top row of table), there was a reasonably consistent pattern of increasing risk of lung cancer with cumulative exposure to crystalline silica. In contrast, the trend for asbestos exposure among workers with the lowest exposure to crystalline silica (left data column) is irregular and hence difficult to interpret. The internal exposure-response analysis also showed an increasing trend with crystalline silica, as the relative risk estimate rose to 1.83 in the highest exposure category. Adjustment for asbestos exposure made only minor differences in the estimates of relative risk. The most striking excess was found for workers with the highest exposures to both crystalline silica and asbestos (SMR 8.31; three observed).

\section{Discussion}

To the extent that the estimates of asbestos exposure are valid, our reanalysis shows that in this cohort asbestos did not confound the association between crystalline silica and lung cancer. The gradient of the relative risk for crystalline silica found here is somewhat weaker than the trend reported in the original study. One of the more probable explanations for the apparently diminished gradient is that workers hired before 1930, for whom the original lung cancer excess was largest (SMR 2.63 ), were not included in this reanalysis. Although asbestos exposure does not seem to have confounded the observed relation with crystalline silica, the increased risk among workers in the highest combined exposure category (SMR 8.31) suggests the possibility of synergy between the two dusts. However, any inference on synergistic effects is probably premature because of the small number of deaths from lung cancer (three) with the largest cumulative exposures.

A mortality update of this cohort, to 1995 , is currently underway. The update will include newly obtained historical dust exposure data that will permit a more direct measurement of exposures to crystalline silica than was possible thus far. Data from radiographic readings for pulmonary fibrosis and pleural abnormali- 
Table continued

\begin{tabular}{|c|c|c|c|c|c|c|c|c|}
\hline \multicolumn{3}{|l|}{$100-199$} & \multicolumn{3}{|l|}{$\geqslant 200$} & \multicolumn{3}{|l|}{ Total } \\
\hline deaths & SMRt & $(95 \% C I)$ & deaths & SMRT & $(95 \% C I)$ & deaths & SMRt & $(95 \% C I)$ \\
\hline $\begin{array}{r}7 \\
2 \\
1 \\
1 \\
11\end{array}$ & $\begin{array}{l}2 \cdot 14 \\
1.11 \\
1.66 \\
6.03 \\
1.89\end{array}$ & $\begin{array}{l}(0.86-4.41) \\
(0.13-4.03) \\
(0.04-9 \cdot 26) \\
(0.15-33 \cdot 6) \\
(0.94-3.37)\end{array}$ & $\begin{array}{r}6 \\
1 \\
0 \\
3 \\
10\end{array}$ & $\begin{array}{l}2 \cdot 00 \\
0 \cdot 59 \\
0 \\
8 \cdot 31 \\
1 \cdot 82\end{array}$ & $\begin{array}{l}(0 \cdot 73-4 \cdot 35) \\
(0 \cdot 01-3 \cdot 30) \\
(0-8 \cdot 44) \\
(1 \cdot 71-24 \cdot 3) \\
(0 \cdot 87-3 \cdot 35)\end{array}$ & $\begin{array}{r}31 \\
12 \\
5 \\
4 \\
52\end{array}$ & $\begin{array}{l}1.34 \\
1.15 \\
1.99 \\
4.40 \\
1.41\end{array}$ & $\begin{array}{l}(0.91-1.91) \\
(0.59-2.01) \\
(0.65-4.64) \\
(1.20-11.3) \\
(1.05-1.85)\end{array}$ \\
\hline 1.81 & & $(0.83-3 \cdot 94)$ & 1.83 & & $(0 \cdot 79-4 \cdot 25)$ & - & & - \\
\hline $1 \cdot 80$ & & $(0.82-3.92)$ & 1.79 & & $(0 \cdot 77-4 \cdot 18)$ & - & & - \\
\hline
\end{tabular}

ties will also be incorporated in the update. This should provide a more precise characterisation of the independent and joint effects of exposures to crystalline silica and asbestos on mortality from lung cancer among these workers in the diatomite industry.

This research was supported by a grant from the United States National Institute for Occupational Safety and Health (R01 $\mathrm{OH03126)}$. The reconstruction of asbestos exposure, by $\mathrm{Dr}$ Gibbs and Mr Christensen, was supported by a contract from the International Diatomite Producers Association, San
Francisco, CA. We are grateful to Ms Jennifer Rene for preparation of the manuscript.

1 Checkoway H, Heyer NJ, Demers PA, Breslow NE. Mortality $\mathrm{H}$, Heyer NJ, Demers PA, Breslow NE. Mortality among workers in the diat

2 Gibbs GW, Christensen DR. The asbestos exposure of workers in the Manville diatomaceous earth plant, Final report to the International Diatomite Producers Association. Lompoc, California: International Diatomite Producers Association, 1994.

3 Dement JM, Brown DP, Okun A. Follow-up study of chrysotile asbestos textile workers: cohort mortality and case-control analyses. Am f Ind Med 1994;26:431-47.

4 Breslow NE, Day NE. Statistical methods in cancer research. Vol. II. The analysis of cohort studies. Lyon: International Agency for Research on Cancer, 1987.

\section{Vancouver style}

All manuscripts submitted to Occup Environ Med should conform to the uniform requirements for manuscripts submitted to biomedical journals (known as the Vancouver style.)

Occup Environ Med, together with many other international biomedical journals, has agreed to accept articles prepared in accordance with the Vancouver style. The style (described in full in the $B M F, 24$ February $1979, \mathrm{p} 532$ ) is intended to standardise requirements for authors.

References should be numbered consecutively in the order in which they are first mentioned in the text by Arabic numerals above the line on each occasion the reference is cited (Manson ${ }^{1}$ confirmed other reports $^{2-5}$... .). In future references to papers submitted to Occup Environ Med should include: the names of all authors if there are seven or less or, if there are more, the first six followed by et al; the title of journal articles or book chapters; the titles of journals abbreviated according to the style of Index Medicus; and the first and final page numbers of the article or chapter. Titles not in Index Medicus should be given in full.

Examples of common forms of references are:

1 International Steering Committee of Medical Editors, Uniform requirements for manuscripts submitted to biomedical journals. Br Med f 1979;1:532-5.

2 Soter NA, Wasserman SI, Austen KF. Cold urticaria: release into the circulation of histamine and eosinohil chemotactic factor of anaphylaxis during cold challenge. N Engl f Med 1976;294:687-90.

3 Weinstein L Swartz MN. Pathogenic properties of invading micro-organisms. In: Sodeman WA Jr, Sodeman WA, eds. Pathologic physiology, mechanisms of disease. Philadelphia: W B Saunders, 1974:457-72. 